\title{
Validity and reliability of the Arabic short version of the child oral health-related quality of life questionnaire (CPQ 11-14) in Medina, Saudi Arabia
}

A. Bhayat ${ }^{1}$ and M.A.M. Ali ${ }^{2}$

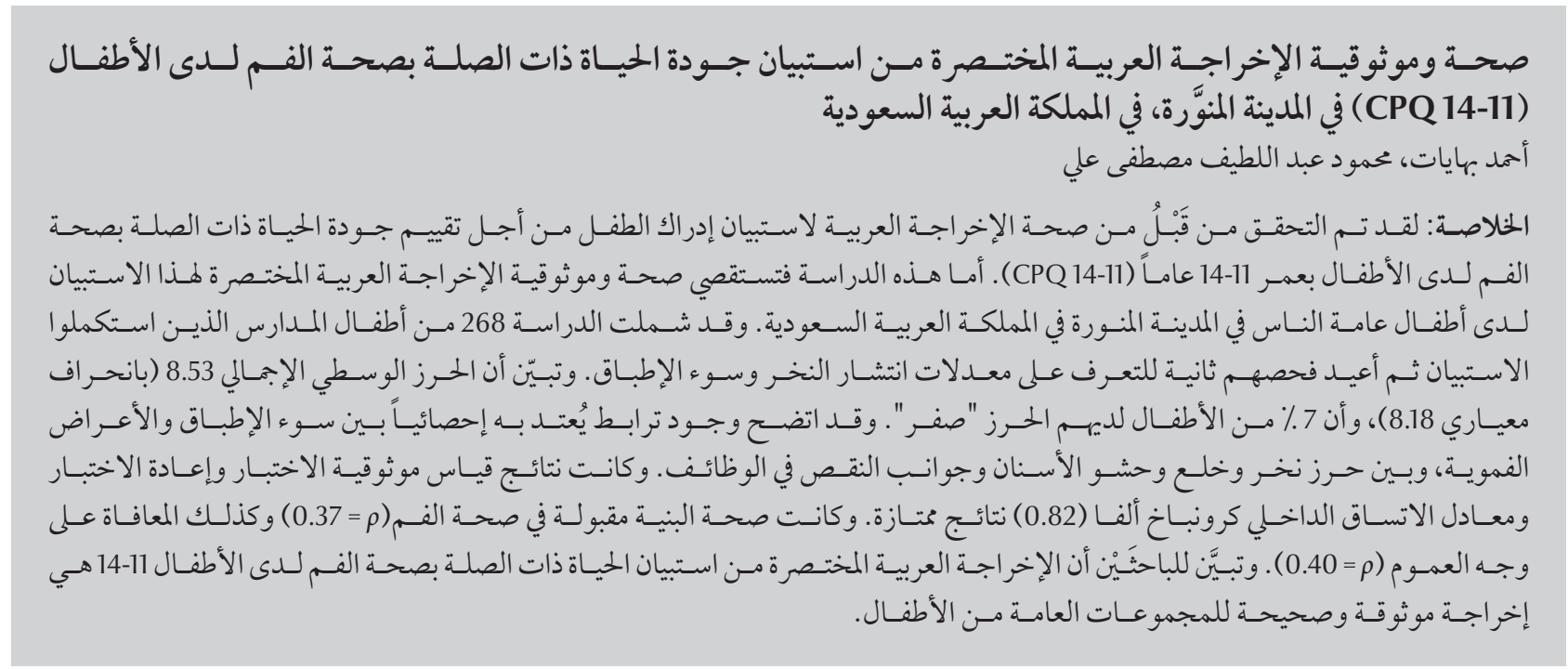

ABSTRACT The Arabic version of the Child Perception Questionnaire for assessing oral health-related quality of life in 11-14 year olds (CPQ 11-14) has been previously validated. This study tested the validity and reliability of the short version of the Arabic CPQ 11-14 in the general population of Medina, Saudi Arabia. A total of 268 schoolchildren completed the questionnaire and were examined to determine the prevalence of caries and malocclusion. The mean total score was 8.53 (SD 8.18), and 7\% of children scored zero. There was a significant association between malocclusion and oral symptoms and between DMFT score and functional limitations. The test-retest reliability (0.78) and Cronbach alpha (0.82) were excellent. The construct validity was acceptable for oral health $(\rho=0.37)$ and overall well-being $(\rho=0.40)$. The Arabic version of the short form CPQ 11-14 was reliable and valid for this general population of children.

Validité et fiabilité de la version abrégée du questionnaire CPQ11-14 en langue arabe sur la qualité de vie liée à la santé bucco-dentaire chez l'enfant à Médine (Arabie saoudite)

RÉSUMÉ La version en langue arabe du Child Perception Questionnaire visant à évaluer la qualité de vie liée à la santé bucco-dentaire chez l'enfant de 11 à 14 ans (CPQ 11-14) a déjà été validée. La présente étude a testé la validité et la fiabilité de la version abrégée du questionnaire CPQ 11-14 en langue arabe auprès de la population générale de Médine (Arabie saoudite). Au total, 268 écoliers ont rempli le questionnaire puis ont été examinés pour déterminer la prévalence des caries et des malocclusions. Le score total moyen était de 8,53 (ET 8,18), et 7 \% des enfants ont obtenu un score de zéro. Il existait une forte association entre la malocclusion et les symptômes buccaux ainsi qu'entre le score pour l'indice des dents cariées, absentes ou obturées (ou CAO) et les limites fonctionnelles. La fiabilité d'un test-retest $(0,78)$ et le coefficient alpha de Cronbach $(0,82)$ étaient excellents. La validité du construit était acceptable pour la santé bucco-dentaire $(\rho=0,37)$ et pour le bien-être général ( $\rho=$ 0,40). La version abrégée du questionnaire CPQ 11-14 en langue arabe est fiable et valable pour cette population générale d'enfants. 


\section{Introduction}

Oral health is an essential component of general health and directly impacts individuals' quality of life (QoL), affecting whether they can eat, talk and socialize without any discomfort or embarrassment (1). It is therefore necessary to measure the QoL related to dental care as it impacts on a variety of medical, social and economic factors in an individual's life. QoL questionnaires are self-administered and aim to quantify the degree to which dental and oral disorders affect daily life (2). The most commonly used questionnaires for children are the Child Oral Health Quality of Life (COH QoL) and the Child Oral Impacts on Daily Performances questionnaires (3). The $\mathrm{COH}$ QoL quantifies the effects that oral and orofacial conditions may have on the well-being of 6-14-year-olds and their families. One of its components, the Child Perceptions Questionnaire for children aged 11-14 years (CPQ 11-14), has been used extensively throughout the world including Saudi Arabia (2,4-6). It consists of 37 items divided into 4 domains and contains an additional 2 questions related to the individual's overall oral health, which act as a validity check. As many authors felt that this questionnaire was too cumbersome and could be effectively reduced and still obtain similar outcomes $(2,6)$, a shorter version was developed (3).

This shorter version has been successfully used in NewZealand (4), Brazil (5), China (7) and Denmark (8). However, it has not been validated in Arabic in a Saudi Arabian population and this is the first study to validate and test its reliability in an Arab setting. The short form consists of 16 questions aimed at measuring the oral health-related $\mathrm{QoL}$ in children and adolescents (3). It consists of 4 domains - oral symptoms, functional limitations, emotional and social well-being — and has 2 additional items related to the child's global rating, which act as a validity check.
The aim of this study was to assess the validity and reliability of the Arabic translation of the short-form version of the CPQ 11-14 questionnaire in a general population of 12-14-year-old Saudi Arabian children.

\section{Methods}

\section{Study design and sample}

This was a cross-sectional, analytical study done on grade 6 students (12-14 years old) in Medina, Saudi Arabia. The schools in Saudi Arabia are segregated according to gender and since the investigators were males, only male schools were included. Out of a total of 42 intermediate male schools, 4 schools were randomly selected. All grade 6 students registered at each school in 2013 were given consent forms. A total of 295 students were registered and all of them received a consent form to be signed by their parents/guardians. A covering letter together with the consent form was provided to the parents explaining the rationale for the study and only if signed consent was received was the child enrolled in the study.

\section{Data collection}

\section{Questionnaire data}

The standardized short questionnaire, which has been validated in New Zealand, Brazil, China and Denmark, was used. This shortened form consists of 18 closed-ended questions which have been obtained from the original full version questionnaire. The questions used in the current Arabic short version were obtained from the full-length Arabic version as validated by Brown et al. (2). It was self-administered and completed by each student after the oral examination.

The first 2 questions related to the global rating of oral health (excellent, very good, good, acceptable or bad) and the extent to which oral health affected overall well-being (not at all, very little, somewhat, a lot or very much). The remaining 16 questions were divided into 4 domains: oral symptoms $(n=4)$; functional limitation $(n=4)$, emotional well-being $(n=4)$ and social well-being $(n=4)$. The responses were scored as follows: for global rating of oral health: (0) excellent, (1) very good, (2) good, (3) acceptable or (4) bad. For the overall condition of oral health, responses were scored as follows: (0) not at all, (1) very little, (2) somewhat, (3) a lot or (4) very much. For the rest of the questions the scores were recorded as follows: (0) never, (1) very little, (2) somewhat, (3) a lot or (4) very much. There were 18 questions and the scores ranged from 0 to 72 , with lower scores representing a high QoL. Each domain was also added separately to give a mean domain score.

The questionnaire was given to the students on the day of the school visit and before the clinical examination. While examining the student, the clinician went through the questionnaire to ensure that all questions were complete and addressed any problems or questions the students may have had while completing the questionnaire.

\section{Clinical data}

The clinical data were obtained by 4 calibrated dentists. Data were collected using World Health Organization guidelines (9). The clinical examinations were done in the school classroom using standard room lighting with the child sitting on a school chair. Dental decay was recorded using the decayed/ missing/filled teeth (DMFT) index and the mean DMFT score was calculated. Malocclusion was classified on the skeletal dental jaw relationship as class I, class II or class III according to Angles' classification (10). Class I was considered as normal occlusion while classes II and III were combined and classified as malocclusion present.

\section{Ethical considerations}

Ethical clearance was obtained from the Taibah University Dental Ethics Committee. The study was performed in accordance with the ethical standards laid 
down by the Declaration of Helsinki (1964) and its later amendments. All data collection forms were anonymous and the data were kept strictly confidential.

\section{Statistical analysis}

The data were entered into the SPSS statistical software package, version 15.0, and the following descriptive statistics were obtained: means, standard deviation (SD), range and frequency of the total scores and the domain subscale scores. The construct validity was calculated by establishing the strength of the association between the total and subscale scores and the scores for the global rating of oral health and overall well-being using Spearman rank correlation coefficient. The discriminant validity was measured by the association between the scores of the clinical findings (caries and malocclusion) and total and subtotal scores using Spearman rank correlation coefficients. The reliability was determined using tests of internal consistency and stability. The degree of uniformity of the scales was assessed using Cronbach alpha to calculate the extent of agreement between the total scale and domain scores. The stability was calculated using the testretest approach. The intraclass correlation coefficient with a $95 \%$ confidence interval $(\mathrm{CI})$ was determined based on repeated interviews of a sample of 52 participants.

\section{Results}

A total of 268 schoolchildren (91\%) completed the questionnaire. After a week, the researchers went back to the schools and 52 schoolchildren completed the questionnaire a second time. All were males (100\%) between 12 and 14 years old. The total scale score (excluding the first 2 questions on the global rating and overall well-being) ranged from 0 to 46 with a mean of 8.53 (SD 8.18). No child obtained a maximum score of 64 , and $7 \%$ of respondents had a score of zero. Almost two-thirds of the respondents reported having oral symptoms or limitations in their oral function in the past 3 months (62\% and $63 \%$ respectively); $37 \%$ reported having emotional problems and 23\% stated that they had social problems as a result of their oral status.

\section{Discriminant validity}

When associating the malocclusion status with the total and subscale scores, the only significant relationship was between malocclusion and oral symptoms; the mean score on the $\mathrm{CPQ}$ 11-14 was 3.28 (SD 2.76) for children with normal malocclusion and 4.40 (SD 2.92) for those with malocclusion $(P=0.002)$ (Table 1).

When correlating the total and subscale scores with the caries status, only the functional limitations variable was significantly associated with the DMFT score, albeit a weak correlation (Spear$\operatorname{man} \rho=0.13, P=0.036)($ Table 2$)$.

\section{Construct validity}

To test for construct validity, Spearman correlations were used. There was a highly significant correlation of overall well-being with the total scale score ( $\rho$ $=0.40)$ and with the scores on all 4 subscales ( $\rho$ ranging from 0.23 to 0.34 ) (all $P<0.001$ ). There were also highly significant correlations of the oral health global indicator with the total scale score $(\rho=0.37)$ and also with the scores on 2 of the subscales: oral symptoms ( $\rho$ $=0.32)$ and emotional well-being $(\rho=$ 0.28) $(P<0.001)($ Table 3$)$.

\section{Reliability}

The reliability was assessed using internal consistency and stability tests. Cronbach alpha was used to detect internal consistency and it was found to be 0.82 for the total scale. For the subscales the values ranged from 0.88 for emotional well-being to 0.62 for functional limitations. The stability of the total scale was calculated using the test-retest reliability and was found to be 0.78 (95\% CI: 0.75-0.82) $(P<$ 0.001) (Table 4).

\section{Discussion}

The overall mean score on the Arabic version of the CPQ 11-14 short form (8.53) was lower than that reported in

\begin{tabular}{|c|c|c|c|}
\hline \multirow[t]{2}{*}{ Variable } & \multicolumn{2}{|c|}{ Mean (SD) score } & \multirow[t]{2}{*}{$P$-value ${ }^{a}$} \\
\hline & $\begin{array}{l}\text { Normal occlusion } \\
\qquad(n=196)\end{array}$ & $\begin{array}{l}\text { Malocclusion present } \\
\qquad(n=72)\end{array}$ & \\
\hline Total scale & $8.20(8.33)$ & $9.43(7.76)$ & 0.061 \\
\hline \multicolumn{4}{|l|}{ Subscales } \\
\hline Oral symptoms & $3.28(2.76)$ & $4.40(2.92)$ & 0.002 \\
\hline Functional limitations & $1.98(2.41)$ & $2.32(2.29)$ & 0.160 \\
\hline Emotional well-being & $1.86(3.52)$ & $1.94(3.34)$ & 0.893 \\
\hline Social well-being & $1.08(2.76)$ & $0.76(1.87)$ & 0.358 \\
\hline
\end{tabular}




\begin{tabular}{|c|c|c|}
\hline \multirow[t]{2}{*}{ Variable } & \multicolumn{2}{|c|}{ DMFT score } \\
\hline & Spearman $\rho$ & $P$-value \\
\hline Total scale & 0.09 & 0.133 \\
\hline \multicolumn{3}{|l|}{ Subscales } \\
\hline Oral symptoms & 0.08 & 0.210 \\
\hline Functional limitations & 0.13 & 0.036 \\
\hline Emotional well-being & 0.01 & 0.878 \\
\hline Social well-being & 0.03 & 0.611 \\
\hline
\end{tabular}

a Brazilian study by Torres et al. (11.9) (5). In addition, the prevalence of a zero score $(7 \%)$ was much higher in this Saudi population compared with the Brazilian cohort (2.9\%). This means that more Saudi children than Brazilian children reported that dental problems had less or no impact on the quality of their life. This could be due to their lower caries scores compared with the Brazilian cohort and to differences in culture, diet and levels of knowledge (2).

Unlike the United Kingdom study by Marshman et al. (11) and the Saudi Arabian study (2) which showed a significant difference in the mean CPQ 11-14 scores for total scales and the presence or absence of malocclusions, the current study showed no difference. This could be attributed to the fact that both of these studies included children form orthodontic practices who were receiving treatment for malocclusion and hence were more aware of their malocclusion status. The current study used schoolchildren and it is possible that they were not aware of their malocclusion status and hence did not experience problems with their overall health or well-being. These results are similar to those reported by Taylor et al. who concluded that malocclusion did not affect QoL in terms of dentistry to a measurable degree (12). It must be noted, however, that the sample from Taylor et al.'s study was obtained from orthodontic and dental clinics and not from the general school-based population.

There was no significant association between caries status and total and subscale scores, and this was also reported by other studies $(11,13,14)$. This could be due to the fact that QoL is influenced by many factors such as the personality, culture, environmental surroundings and others, as discussed

\begin{tabular}{|c|c|c|c|c|}
\hline $\begin{array}{l}\text { Table } 3 \text { Construct validity } \\
\text { and the total and subscal } \\
\text { related quality of life que }\end{array}$ & $\begin{array}{l}\text { orrelation b } \\
\text { cores on the } \\
\text { onnaire (CP }\end{array}$ & $\begin{array}{l}\text { een oral } \\
\text { ort versic } \\
-14)\end{array}$ & $\begin{array}{l}\text { Ith and over } \\
\text { f the child o }\end{array}$ & $\begin{array}{l}\text { vell-being } \\
\text { lealth- }\end{array}$ \\
\hline Variable & & relation v & h global ratin & \\
\hline & Oral I & Ith & Overall w & -being \\
\hline & Spearman $\rho$ & $P$-value & Spearman $\rho$ & $P$-value \\
\hline Total scale & 0.37 & 0.001 & 0.40 & 0.001 \\
\hline Subscales & & & & \\
\hline Oral symptoms & 0.32 & 0.001 & 0.34 & 0.001 \\
\hline Functional limitations & 0.18 & 0.003 & 0.23 & 0.001 \\
\hline Emotional well-being & 0.28 & 0.001 & 0.28 & 0.001 \\
\hline Social well-being & 0.12 & 0.048 & 0.24 & 0.001 \\
\hline
\end{tabular}

by O'Connor (15). Although it seems that dental caries does not directly affect the QoL in this population, it must be noted that there were relatively strong associations between oral symptoms and DMFT scores and these results are similar to those of other studies (2).

Construct validity of the Arabic version of the short form CPQ 11-14 showed moderate correlations between the total scores and the global oral health question and the overall health question. These results ( $\rho=0.37$ and 0.40 respectively) were similar to other studies $(\rho=0.38$ and 0.39$)(14)$ and ( $\rho=0.35$ and 0.32 respectively) (13). However, the validity scores were lower compared with studies evaluating oral health QoL in adults. An Arab study reported validity scores of $\rho=0.51$ and 0.59 (16), while a study on Hungarian adults reported validity scores of $\rho$ $=0.40$ and 0.64 (17). The difference confirms the assumption that the relationship between the QoL related to oral health in adults as measured by a global indicator is different from that in children

Similar to Brown et al. (2) we found a significant relationship between the global oral health rating and all the subscale scores. However, unlike Brown et al., who did not find a significant association between the global overall well-being and the subscales, the shortened version of the Arabic CPQ 11-14 showed significant associations between these variables. The differences could be due to differences in race and education, as stated by other authors (18).

The intraclass correlation coefficient was higher (0.78) compared with that reported by Brown et al. (0.65) (2) but not as high as in the Brazilian study (0.97) (5). According to the guidelines set by Nunnally et al. a score over 0.75 is considered excellent (19) and hence the total score and the emotional and social well-being scores could be judged as having excellent 


$\begin{aligned} & \text { Table } 4 \text { Reliability statistics for total and subscale scores on the short version of } \\
& \text { the child oral health-related quality of life questionnaire }(\mathrm{CPQ} 11-14)(\boldsymbol{n}=\mathbf{5 2})\end{aligned}$
\begin{tabular}{lccc} 
Variable & No. of items & Cronbach $\boldsymbol{\alpha}$ & $\begin{array}{c}\text { Intraclass correlation } \\
\text { coefficient }(\mathbf{9 5} \% \mathbf{C I})^{\mathrm{a}}\end{array}$ \\
$\begin{array}{l}\text { Total scale } \\
\text { Subscales }\end{array}$ & 16 & 0.82 & $0.78(0.75-0.82)$ \\
$\quad$ Oral symptoms & 4 & 0.68 & $0.59(0.57-0.69)$ \\
Functional limitations & 4 & 0.62 & $0.61(0.56-0.63)$ \\
Emotional well-being & 4 & 0.88 & $0.88(0.85-0.90)$ \\
Social well-being & 4 & 0.86 & $0.86(0.84-0.89)$ \\
\hline
\end{tabular}

${ }^{a}$ One-way random effect model: $P<0.001$ for all values. $\mathrm{Cl}=$ confidence interval.

reliability. The remaining 2 subscales achieved good reliability scores. These variations could be attributed to the translation of the questionnaire and the understanding of the questions by the subjects. However, the Cronbach alpha coefficient in the current study (0.82) was high, as a reliability score greater than 0.5 is considered acceptable (20). This was similar to other studies (13,21), in which Cronbach alpha ranged between 0.81 and 0.91 . This indicated that the short version of the Arabic questionnaire demonstrated good reliability scores for the total and subscale scores.
However, it was noted that, although the questionnaire used spoken Arabic, students had difficulty reading and answering the questionnaire. It is therefore recommended to have an interview rather than a self-administered questionnaire, similar to the recommendation of Brown et al. (2). Another option would be to consider rewording the questionnaire and making it easier for the students to understand; this would eliminate the need for an interviewer and reduce costs and time.

One of the limitations of the study was that only males were included. This could have skewed the results, but other similar articles have not shown any difference in scores between the sexes. However, we are planning to carry out the same study among females in the future.

\section{Conclusion}

The shortened version of the Arabic CPQ 11-14 questionnaire was found to be a reliable and valid instrument to measure the dental QoL in 12-14-year-old children within the general population of Medina. However, more research is required on Saudi communities with different needs and in different settings.

\section{Acknowledgements}

We would like to thank the final-year dental students for their invaluable help in data collection and data entering. We would also like to thank Dr Sami Ahmad for his help and assistance with this project.

\section{Funding: None.}

Competing interests: None declared.

\section{References}

1. WHO oral health data bank. Geneva: World Health Organization; 2002.

2. Brown A, Al-Khayal Z. Validity and reliability of the Arabic translation of the child oral-health-related quality of life questionnaire (CPQ11-14) in Saudi Arabia. Int J Paediatr Dent. 2006 Nov;16(6):405-11. PMID:17014538

3. Jokovic A, Locker D, Guyatt G. Short forms of the Child Perceptions Questionnaire for 11-14-year-old children (CPQ11-14): development and initial evaluation. Health Qual Life Outcomes. 2006;4(1):4-14. PMID:16423298

4. Page LA, Thomson WM, Mohamed AR, Traebert J. Performance and cross-cultural comparison of the short-form version of the CPQ11-14 in New Zealand, Brunei and Brazil. Health Qual Life Outcomes. 2011;9(1):40-8. PMID:21649928

5. Torres CS, Paiva SM, Vale MP, Pordeus IA, Ramos-Jorge ML, Oliveira AC, et al. Psychometric properties of the Brazilian version of the Child Perceptions Questionnaire (CPQ1114)-short forms. Health Qual Life Outcomes. 2009;7(1):43. PMID:19445725

6. McGrath C, Pang HN, Lo EC, King NM, Hägg U, Samman N. Translation and evaluation of a Chinese version of the child Oral Health-related Quality of Life measure. Int J Paediatr Dent. 2008 Jul;18(4):267-74. PMID:18554335
7. Li XJ, Huang H, Lin T, Huang GM. [Validation of a Chinese version of the child perception questionnaire]. Hua Xi Kou Qiang Yi Xue Za Zhi. 2008 Jun;26(3):267-70 (in Chinese). PMID:18705508

8. Wogelius P, Gjørup H, Haubek D, Lopez R, Poulsen S. Development of Danish version of child oral-health-related quality of life questionnaires (CPQ8-10 and CPQ11-14). BMC Oral Health. 2009;9(1):11. PMID:19383176

9. Oral health surveys: basic methods. Geneva: World Health Organization; 1997.

10. Angle EH. Classification of malocclusion. Dent Cosmos. 1988;41:248-64.

11. Marshman Z, Rodd H, Stern M, Mitchell C, Locker D, Jokovic A, et al. An evaluation of the Child Perceptions Questionnaire in the UK. Community Dent Health. 2005 Sep;22(3):151-5. PMID:16161878

12. Taylor KR, Kiyak A, Huang GJ, Greenlee GM, Jolley CJ, King GJ. Effects of malocclusion and its treatment on the quality of life of adolescents. Am J Orthod Dentofacial Orthop. 2009 Sep;136(3):382-92. PMID:19732673

13. Bekes K, John MT, Zyriax R, Schaller HG, Hirsch C. The German version of the Child Perceptions Questionnaire (CPQG11-14): translation process, reliability, and validity in the 
general population. Clin Oral Investig. 2012 Feb;16(1):165-71. PMID:21210166

14. Barbosa TS, Tureli MC, Gavião MB. Validity and reliability of the Child Perceptions Questionnaires applied in Brazilian children. BMC Oral Health. 2009;9(1):13.

15. O'Connor R. Measuring quality of life in health. Edinburgh: Churchill Livingstone; 2004.

16. Al-Jundi MA, Szentpétery A, John MT. An Arabic version of the Oral Health Impact Profile: translation and psychometric properties. Int Dent J. 2007 Apr;57(2):84-92. PMID:17506467

17. Szentpétery A, Szabó G, Marada G, Szántó I, John MT. The Hungarian version of the Oral Health Impact Profile. Eur J Oral Sci. 2006 Jun;114(3):197-203. PMID:16776768
18. Krause NM, Jay GM. What do global self-rated health items measure? Med Care. 1994 Sep;32(9):930-42. PMID:8090045

19. Nunnally JC, Bernstein IR. Psychometric theory. New York: McGraw-Hill; 1994.

20. Cronbach LJ. Coefficient alpha and the internal structure of tests. Psychometrika. 1951;16(3):297-334.

21. Foster Page LA, Thomson WM, Jokovic A, Locker D. Epidemiological evaluation of short-form versions of the Child Perception Questionnaire. Eur J Oral Sci. 2008 Dec;116(6):538-44. PMID:19049524 